\title{
Doenças da pele em caprinos e ovinos no semi-árido brasileiro $^{1}$
}

\author{
Juliana T.S.A. Macêdo², Franklin Riet-Correa ${ }^{2}$, Antônio Flávio Medeiros \\ Dantas $^{2}$ e Sara Vilar Dantas Simões ${ }^{2}$
}

\begin{abstract}
Macêdo J.T.S.A., Riet-Correa F., Dantas A.F.M. \& Simões S.V.D. 2008. [Diseases of the skin in sheep and goats from the Brazilian semiarid.] Doenças da pele em ovinos e caprinos no semi-árido brasileiro. Pesquisa Veterinária Brasileira 28(12):633-642. Hospital Veterinário, Cento de Saúde e Tecnologia Rural, Universidade Federal de Campina Grande, Campus de Patos, 58700-000 Patos, PB, Brazil. E-mail: franklin.riet@pq.cnpq.br

A study of the skin diseases in sheep and goats in the semiarid of the states of Paraíba, Pernambuco and Rio Grande do Norte, Northeastern Brazil was performed. From January 2000 to November 2006, 656 cases in goats and 324 in sheep were presented to the Veterinary Hospital of the Federal University of Campina Grande in Patos, Paraíba. Additionally mailed in biopsy or necropsy skin samples from 31 goats and 45 sheep were studied histologically. Skin diseases were diagnosed in 35 goats $(5.33 \%$ of all cases in this species) and 45 sheep (13.88\% of the cases in this species). The most frequent skin disease was myiasis (10 cases in goats and 7 in sheep), followed by contagious echtyma ( 8 cases in goats and 2 in sheep), squamous cell carcinoma (4 cases in goats and 5 in sheep), dermatophylosis (8 cases in sheep), and allergic dermatitis ( 1 case in goats and 1 in sheep). Two cases of pythiosis in sheep, two cases of epidermolysis bullosa in goats, one case of poisoning by Brachiaria brizantha (photosensitization) and another by Leucaena leucocephala (alopecia) in sheep, and one case of papillomatosis, one of pemphigus foliaceous, one of protothecosis and one of rhabdomyosarcoma in goats were also diagnosed. In 4 cases in sheep and 19 in goats the etiologic diagnosis was not obtained. With the information of the occurrence and epidemiology of the skin diseases is possible to determine efficient control measures.
\end{abstract}

INDEX TERMS: Squamous cell carcinoma, dermatophylosis, epidermolysis bullosa, contagious echtyma, myiasis.

RESUMO.- Foi realizado um estudo das doenças de pele diagnosticadas em ovinos e caprinos, no semi-árido dos Estados da Paraíba, Pernambuco e Rio Grande do Norte. De janeiro de 2000 a novembro de 2006 foram registrados no Hospital Veterinário da Universidade Federal de Campina Grande, em Patos, Paraíba, 656 diagnósticos em caprinos e 324 em ovinos, além do estudo de espécimes de necropsia ou biópsia da pele de 31 em caprinos e 45 em ovinos enviados para exame histológico. Dos casos

\footnotetext{
${ }^{1}$ Recebido em 27 de maio de 2008.

Aceito para publicação em 19 de julho de 2008.

${ }^{2}$ Hospital Veterinário, Centro de Saúde e Tecnologia Rural (CSTR), Universidade Federal de Campina Grande, Campus de Patos, 58700-970 Patos, PB, Brasil. *Autor para correspondência: franklin.riet@pq.cnpq.br
}

atendidos $80(8,16 \%)$ apresentavam alterações na pele, destes 35 ocorreram em caprinos $(5,33 \%$ do total de casos diagnosticados nesta espécie) e 45 em ovinos (13,88\% dos casos diagnosticados nesta espécie). Das doenças de pele, a mais freqüente foi a miíase (10 casos em caprinos e 7 em ovinos) seguida do ectima contagioso (8 casos em caprinos e 2 em ovinos), carcinoma epidermoide (4 casos em caprinos e 5 em ovinos), dermatofilose (8 casos em ovinos), dermatite alérgica (1 caso em ovino e 1 em caprino). Além disso, foram diagnosticados dois casos de pitiose em ovinos, dois casos de epidermólise bolhosa em caprinos, um caso de intoxicação por Brachiaria brizantha (fotossensibilização) e outro de intoxicação por Leucaena leucocephala (alopecia) em ovinos e um caso de papilomatose, um de pênfigo foliáceo, um de 
prototecose e um de rabdomiossarcoma em caprinos. Em 4 casos em ovinos e 19 em caprinos não foi realizado diagnóstico etiológico da doença. A informação gerada sobre a ocorrência e epidemiologia das doenças de pele permite estabelecer medidas adequadas de controle.

TERMOS DE INDEXAÇÃO: Carcinomas epidermóides, dermatofilose, epidermólise bolhosa, ectima contagioso, miíases.

\section{INTRODUÇÃO}

A região Nordeste atualmente detém grande parte do rebanho caprino e ovino brasileiro. Muitos destes animais pertencem a rebanhos de pequenos produtores e são uma importante fonte de renda resultante da venda da sua carne e couro. Sabe-se que o valor da pele perfaz $20 \%$ do valor do animal; conseqüentemente a pele constitui uma receita importante para o produtor e gera divisas para 0 país (Nogueira Filho 2003). Dessa forma, o conhecimento das doenças da pele, que diminuem a qualidade desta matéria prima e que, além disso, causam diminuição no ganho de peso e até a morte do animal, é de interesse para a região. Por outro lado, o conhecimento das doenças é importante para determinar formas eficientes de controle e profilaxia das mesmas. Para cumprir este objetivo o Hospital Veterinário da Universidade Federal de Campina Grande vem realizando diagnóstico sistemático das doenças de ruminantes e eqüinos na área de influência, que abrange principalmente o semi-árido da Paraíba e parte do semi-árido de Pernambuco e Rio Grande no Norte. O objetivo deste trabalho é descrever a epidemiologia, sinais clínicos e patologia das enfermidades da pele de caprinos e ovinos que ocorreram de janeiro de 2000 a novembro de 2006 na região mencionada anteriormente.

\section{MATERIAL E MÉTODOS}

Os arquivos do Laboratório de Patologia Animal (LPA) e da Clínica de Grandes Animais (CGA) do Hospital Veterinário de Patos, da Universidade Federal de Campina Grande, foram revisados no período de janeiro de 2000 a dezembro de 2005, a procura de casos de doenças da pele nos pequenos ruminantes, com levantamento de dados epidemiológicos (espécie, idade, sexo dos animais afetados, data do início da doença, ambiente em que o animal permanecia, freqüência e evolução da doença) e sinais clínicos (presença de prurido, miíase, aspecto macroscópico e localização das lesões). No período, os diagnósticos tinham sido realizados por estudo de raspados de pele para ectoparasitos, dermatomicoses e dermatofilose e por confecção de lâminas histológicas de materiais coletados em biópsias ou necropsias. As lâminas histológicas foram revisadas para a descrição das lesões e, quando necessário, foram feitas novas lâminas a partir dos blocos de parafina ou do material conservado em formol tamponado a $10 \%$. As colorações utilizadas foram hematoxilina e eosina (HE) e ácido periódico de Schiff (PAS).

Durante o ano de 2006 (janeiro-novembro), foi realizado o acompanhamento dos caprinos e ovinos que apresentaram lesões de pele, encaminhados a CGA e ao LPA. Desses foram coletados os dados epidemiológicos por meio de preenchimento de fichas durante a avaliação clínica do animal. Sempre que necessário foi realizada biópsia de pele. Para isso utilizou-se anestesia local com xilocaína a $2 \%$, coletando-se com bisturi fragmentos de pele que foram fixados em formol a $10 \%$, processados em parafina, corados por hematoxilina-eosina (HE) e PAS e observados em microscópio óptico para descrição das lesões provenientes de dermatites bacterianas, virais, imunomediadas, alérgicas, distúrbios hereditários e neoplasias.

Também foram coletados raspados de pele para diagnóstico de sarna, dermatofilose e dermatofitose. Para o diagnóstico de sarna foi realizado o raspado de diversas lesões com auxílio de lâmina de bisturi, sendo o raspado profundo e suficiente para criar transudação capilar. O material obtido foi disposto sobre uma lâmina com óleo mineral, de forma que todo material ficasse imerso, e coberto por uma lamínula de forma que não permanecessem bolhas de ar e examinado em microscópio óptico. Para o diagnóstico de dermatofilose foram coletadas crostas de áreas afetadas, retirando-se os pêlos em excesso. As crostas foram picadas e misturadas a gotas de água sobre uma lâmina, depois de amolecida elas foram esmagadas e distribuídas homogeneamente por toda lâmina. Este material foi secado ao ar livre, fixado por 5 minutos em álcool etílico e corado por 10 minutos com corante de Giemsa ou azul de metileno. Para o diagnóstico de dermatomicose foram coletados pêlos e escamas da periferia de diversos locais com lesão. Após homogeneizado, o material era distribuído sobre uma lâmina, misturado a uma solução de hidróxido de potássio a $10 \%$ até que essa solução clarificasse o material, que era então observado em microscópio de luz a procura de esporos e hifas.

Em um surto de dermatólise, material da orelha de um animal afetado foi retirado cirurgicamente. Um fragmento do material foi fixado em formalina neutra a $10 \%$ e outro fragmento foi fixado em solução de glutaraldeído a $2 \%$ e paraformaldeído a $2 \%$ em tampão cacodilato ( $\mathrm{pH} 7,4)$, pós-fixado em tetróxido de ósmio a $1 \%$, em tampão cacodilato $0,4 \mathrm{M}(\mathrm{pH} 7,4)$, e incluído em Epon 812. Cortes semi-finos foram corados com azul de metileno. Cortes ultrafinos foram contrastados com citrato de chumbo e acetato de uranila e examinados em microscópio eletrônico de transmissão Zeiss EM 109 a 80 quilovolts.

Cada diagnóstico equivale à ocorrência de doença em uma propriedade, podendo se referir tanto a um único animal acometido quanto a um surto. Os casos que apresentavam apenas o diagnóstico clínico com sinais clínicos inespecíficos e que não foram realizados exames complementares para sua confirmação, foram considerados como sem diagnóstico. Os casos referentes à infestação por piolhos não foram analisados.

\section{RESULTADOS}

De janeiro de 2000 a novembro de 2006 foram registrados na CGA 980 diagnósticos de doenças em pequenos ruminantes, desses 656 em caprinos e 324 em ovinos. No LPA-HV, foram registradas 76 necropsias ou biópsias; dessas 31 em caprinos e 45 em ovinos. Dos casos atendidos no CGA, $80(8,16 \%)$ apresentavam alterações na pele; desses 35 ocorreram em caprinos $(5,33 \%$ do total de casos diagnosticados nesta espécie) e 45 em ovinos (13,88\% dos casos diagnosticados nesta espécie) (Quadro 1). As características de cada doença diagnosticada são mencionadas a seguir. 
Quadro 1. Diagnóstico de doenças da pele em caprinos e ovinos no HV no período de janeiro de 2000 a novembro de $2006^{a}$

\begin{tabular}{lccc}
\hline \multicolumn{1}{c}{ Diagnóstico } & \multicolumn{2}{c}{$\begin{array}{c}\text { Espécie / número } \\
\text { de casos }\end{array}$} & Total \\
\cline { 2 - 3 } & Caprinos & Ovinos & \\
\hline Míase & 10 & $7 \mathrm{~b}$ & 17 \\
Ectima contagioso & 8 & 2 & 10 \\
Carcinoma epidermoide & 4 & 5 & 9 \\
Dermatofilose & - & 8 & 8 \\
Melanoma & 2 & - & 2 \\
Dermatite alérgica & 1 & 1 & 2 \\
Epidermólise bolhosa & 2 & - & 2 \\
Pitiose & - & 2 & 2 \\
Intoxicação por Leucaena leucocephala & - & 1 & 1 \\
Fotossensibilizacão por Brachiaria brizantha & - & 1 & 1 \\
Papilomatose & 1 & - & 1 \\
Pênfigo foliáceo & 1 & - & 1 \\
Prototecose & 1 & - & 1 \\
Rabdomiossarcoma & 1 & - & 1 \\
Sem diagnóstico & 4 & 19 & 23 \\
Total & 35 & 45 & 80
\end{tabular}

a Cada diagnóstico equivale à ocorrência de doença em uma propriedade, podendo se referir tanto a um único animal acometido quanto a um surto.

b Deste total, um caso é referente a um ovino com carcinoma epidermóide.

\section{Miíases}

Foram diagnosticados 17 casos de miíases, 10 em caprinos e 7 em ovinos; $55,5 \%$ dos casos ocorreram na época de chuva. O diagnóstico de miíase foi realizado com a observação da lesão e presença das larvas durante o exame clínico. A ocorrência de miíase no período de estudo, correspondeu a $1,52 \%$ das doenças diagnosticadas em caprinos e $2,16 \%$ das doenças diagnosticadas em ovinos. Dados referentes a esses casos são apresentados no Quadro 2.
Em 6 animais com até 1 mês de idade, as lesões localizavam-se na região perianal (Casos 1, 3, 5) e umbigo (Casos 11, 12, 14). Dos animais adultos, seis (Casos 4, 7-10,16) apresentaram miíase após histórico de lesões cortantes. Nos Casos 2 e 5 as mí́ases da vulva ocorreram em lesões decorrentes de parto. Nos Casos 13 e 15, a miíase ocorreu em lesões proliferativas, sangrantes com odor pútrido localizadas no olho (Caso 13) e região perianal (Caso 15). No Caso 6 a miíase se instalou em uma lesão na narina associada carcinoma epidermóide (mesmo animal do Caso 1 de carcinoma epidermóide).

\section{Ectima contagioso}

Foram diagnosticados 10 surtos de ectima contagioso, sendo 8 em caprinos e 2 em ovinos. Esses surtos foram descritos anteriormente (Nóbrega et al. 2008). Os diagnósticos em ectima contagioso corresponderam a $1,21 \%$ e $0,61 \%$ dos casos atendidos na CGA em caprinos e ovinos, respectivamente.

\section{Carcinoma epidermóide}

Foram diagnosticados 10 casos de carcinoma epidermóide, 5 em caprinos e 5 em ovinos. Todos os animais afetados por essa condição eram fêmeas com idade acima de três anos. Do total de casos atendidos na CGA em caprinos e ovinos no período de janeiro de 2000 a novembro de 2006, o diagnóstico de carcinoma epidermóide correspondeu a $0,76 \%$ e $1,54 \%$ das doenças diagnosticadas em caprinos e ovinos, respectivamente. Os dados epidemiológicos referentes a esses casos são apresentados no Quadro 3.

Em sete casos (Casos 2, 4, 5, 6, 7, 9, 10), as lesões caracterizavam-se pelo aspecto granular e proliferativo, superfície ulcerada (Fig.1A,B), úmida com odor pútrido medindo até $6 \mathrm{~cm}$ de diâmetro, exceto o Caso 5 que a

Quadro 2. Dados epidemiológicos referentes aos diagnósticos de miíase em caprinos e ovinos no HV no período de janeiro de 2000 a novembro de 2006

\begin{tabular}{|c|c|c|c|c|c|c|c|c|}
\hline Casos & Espécie & $\begin{array}{l}\text { Local da } \\
\text { lesão }\end{array}$ & Idade & Sexo & Raça & Mês & Ano & Município \\
\hline 1 & Caprino & Perianal & 12 dias & $M^{d}$ & Anglo Nubiana & Abril & 2000 & São José do Bonfim \\
\hline 2 & Caprino & Vulva & 1ano e $6 \mathrm{~m}^{\mathrm{b}}$ & $\mathrm{F}^{\mathrm{e}}$ & SRD $f$ & Julho & 2000 & Patos \\
\hline 3 & Caprino & Perianal & 11 dias & $\mathrm{M}$ & SRD & Setembro & 2000 & Malta \\
\hline 4 & Caprino & Esterno & 2 anos & M & Saanen & Outubro & 2000 & Teixeira \\
\hline 5 & Caprino & Perianal & 30 dias & $M$ & SRD & Novembro & 2000 & Patos \\
\hline 6 & Ovino & Narina & 6 anos & $\mathrm{F}$ & Santa Inês & Junho & 2001 & Malta \\
\hline 7 & Caprino & Pálpebra & 2 anos & $\mathrm{F}$ & SRD & Abril & 2002 & Patos \\
\hline 8 & Caprino & Peito & 5 anos & M & Boer & Maio & 2002 & Pombal \\
\hline 9 & Ovino & MTE ${ }^{a}$ & $\mathrm{Ni}^{\mathrm{C}}$ & $\mathrm{F}$ & $\mathrm{Ni}$ & Abril & 2002 & São José das Espinharas \\
\hline 10 & Ovino & Cotovelo & $\mathrm{Ni}$ & M & SRD & Maio & 2002 & Patos \\
\hline 11 & Ovino & Umbigo & 4 dias & M & SRD & Maio & 2002 & Patos \\
\hline 12 & Ovino & Umbigo & 3 dias & $\mathrm{F}$ & Santa Inês & Maio & 2004 & São Mamede \\
\hline 13 & Ovino & Olho & 2 anos & $\mathrm{F}$ & SRD & Agosto & 2004 & Patos \\
\hline 14 & Ovino & Umbigo & $1 \mathrm{mes}$ & $\mathrm{F}$ & SRD & Agosto & 2004 & Patos \\
\hline 15 & Caprino & Perianal & 1 ano & $\mathrm{F}$ & SRD & Janeiro & 2005 & Patos \\
\hline 16 & Caprino & Dígito & 3 anos & $\mathrm{F}$ & SRD & Maio & 2005 & Patos \\
\hline 17 & Caprino & Vulva & 1 ano e $6 \mathrm{~m}$ & $\mathrm{~F}$ & SRD & Julho & 2006 & Patos \\
\hline
\end{tabular}


Quadro 3. Dados epidemiológicos referentes aos diagnósticos de carcinoma epidermóide em caprinos e ovinos no HV no período de janeiro de 2000 a novembro de 2006

\begin{tabular}{|c|c|c|c|c|c|c|c|}
\hline Casos & Espécie & Idade & $\begin{array}{l}\text { Local da } \\
\text { lesão }\end{array}$ & Raça & Mês & Ano & Município \\
\hline 1 & Ovino & 6 anos & Narina & Santa Inês & Julho & 2001 & Malta \\
\hline 2 & Caprino & $\mathrm{Ni}^{\mathrm{a}}$ & Vulva & $\mathrm{Ni}$ & Maio & 2002 & $\mathrm{Ni}$ \\
\hline 3 & Ovino & 4 anos e 11 meses & $\begin{array}{c}\text { Orelha, reg. abdominal } \\
\text { e periocular }\end{array}$ & Santa Inês & Dezembro & 2002 & Patos \\
\hline 4 & Caprino & 3 anos & Vulva & $\mathrm{SRD}^{\mathrm{b}}$ & Março & 2003 & Patos \\
\hline 5 & Ovino & 3anos e 6 meses & Orelhas & Mestiça Santa Inês & & 2003 & Ilha do Antere \\
\hline 6 & Ovino & 3 anos & Pele abdominal & SRD & Dezembro & 2005 & Campina Grande \\
\hline 7 & Caprino & 7 anos & Ânus, vulva e pálpebra & SRD & Janeiro & 2006 & São José do Bonfim \\
\hline 8 & Ovino & $\mathrm{Ni}$ & Orelha & Bergamacia & Junho & 2006 & $\mathrm{Ni}$ \\
\hline 9 & Caprino & 5 anos & Olho e vulva & Saanen & Julho & 2006 & Barra de Santa Rosa \\
\hline 10 & Caprino & 5 anos & Vulva & Boer & Outubro & 2006 & Campina Grande \\
\hline
\end{tabular}

a $\mathrm{Ni}=$ não informado, ${ }^{b} \mathrm{SRD}=$ sem raça definida.
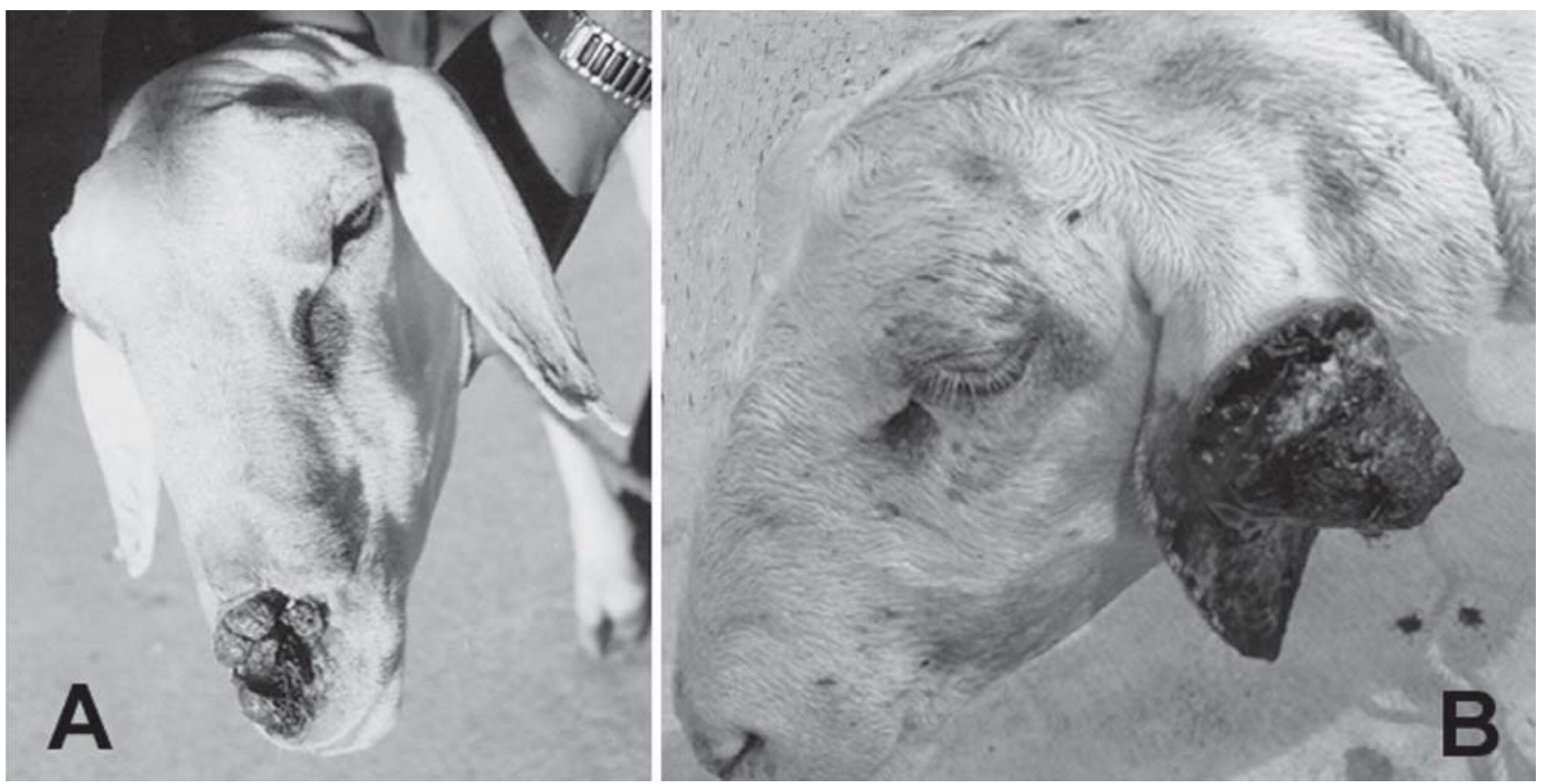

Fig.1. Carcinoma epidermóide. (A) Ovino (Caso 1) com lesão na narina. (B) Ovino (Caso 5) com lesão proliferativa com aspecto granular de superfície ulcerada e necrótica na orelha esquerda.

lesão apresentava o diâmetro de 10cm (Fig.1B). Nos Casos 2 e 4, o crescimento da massa tumoral foi observado por 2-6 meses, sendo relatado que estas lesões foram decorrentes do parto e que não cicatrizaram. O Caso 6 ocorreu em uma ovelha, com histórico inicial de uma lesão parasitada por miíase que foi tratada e que também não cicatrizou. Nos Casos 7 e 10, os animais foram adquiridos já com a lesão. Nos Casos 3 e 8, foram observadas múltiplas lesões proliferativas, queratinizadas, semeIhantes a papilomas. O Caso 1 foi trazido ao HV por apresentar uma ferida na narina, parasitada por mí́ase (Fig.1A). Foi realizada a extirpação cirúrgica da lesão, tratamento tópico e liberado o animal. Em todos os casos, não havia informações nas fichas sobre a evolução após a retirada cirúrgica da lesão ou biópsia.

$\mathrm{Na}$ microscopia as lesões caracterizaram-se por massas tumorais compostas por células com núcleo grande, redondo, levemente basofílico, cromatina granular e nucléolo evidente, citoplasma abundante eosinofílico, com pleomorfismo variável e várias figuras de mitose. Essas células podiam ser observadas dispostas em cordões ou ilhas, infiltrando a derme. Em algumas destas ilhas de células havia queratinização individual ou formando "pérolas" de queratina. O estroma destas massas tumorais era moderado, formado por fibroblastos, disposto em feixes, com infiltrado inflamatório mono e polimorfonuclear. $\mathrm{Na}$ superfície das lesões havia necrose e contaminação bacteriana secundária e na epiderme adjacente à área necrosada observava-se hiperplasia pseudoepiteliomatosa invadindo a derme.

\section{Dermatofilose}

Foram diagnosticados 8 casos de dermatofilose, todos em ovinos. Em 6 casos foram descritos dados refe- 
Quadro 4. Dados epidemiológicos referentes aos diagnósticos de dermatofilose em ovinos no HV no período de janeiro de 2000 a novembro de 2006

\begin{tabular}{cccccccc}
\hline Caso & Idade & Sexo & Raça & $\begin{array}{c}\text { Animais } \\
\text { acometidos }\end{array}$ & Mês & Ano & Município \\
\hline 1 & 2 anos & $\mathrm{Fb}^{\mathrm{b}}$ & SRD & 1 & Julho & 2005 & Patos \\
2 & $\mathrm{Ni}^{\mathrm{n}}$ & $\mathrm{M}^{\mathrm{c}}$ & SRD & 1 & Agosto & 2005 & São Mamede \\
3 & $\mathrm{Ni}$ & $\mathrm{F}$ & SRD & 1 & Novembro & 2005 & Ni \\
4 & Adulta & $\mathrm{F}$ & SRD & 16 & Abril & 2006 & Santa Luzia \\
5 & Adulta & $\mathrm{F}$ & Mestiça Santa Inês & 40 & Abril & 2006 & São Mamede \\
6 & 18 dias & $\mathrm{F}$ & Santa Inês & 1 & Junho & 2006 & São José do Egito \\
7 & 5 anos & $\mathrm{M}$ & SRD & 1 & Setembro & 2006 & Trincheira \\
8 & 3 anos & $\mathrm{F}$ & Mestiça Santa Inês & 1 & Setembro & 2006 & Patos
\end{tabular}

$\overline{\mathrm{a}} \mathrm{Ni}=$ não informado, ${ }^{\mathrm{b}} \mathrm{F}=$ fêmea; ${ }^{\mathrm{c}} \mathrm{M}=$ macho, ${ }^{\mathrm{d}} \mathrm{SRD}=$ sem raça definida.

rentes a animais trazidos ao HV em que não foi informado se haviam outros casos da doença no rebanho ou porque a queixa principal não era a lesão da pele (Casos 1, 3, 6 e 8). Em duas oportunidades (Casos 4 e 5) a doença ocorreu em forma de surtos. Os casos de dermatofilose corresponderam a 2,46\% das doenças diagnosticadas em ovinos na CGA. Os dados referentes a estes casos apresentam-se no Quadro 4.

Em seis casos (Casos 1, 2, 3, 6, 7 e 8), os animais apresentavam áreas de alopecia com descamação e formação de crostas e desprendimento de pêlos, localizadas nas orelhas, região dorsal e lombar. O Caso 1 foi trazido ao $\mathrm{HV}$, por apresentar prolapso de vagina. O Caso 3 foi trazido ao HV por apresentar decúbito esternal permanente, anorexia e caquexia; o exame parasitológico de fezes demonstrou alta infestação de helmintos. $O$ animal estava muito debilitado e morreu. O Caso 6 ocorreu em uma cordeira, que foi trazida ao HV por apresentar malformação de membros e face e em péssimo estado corporal. Foi submetida a eutanásia e na necropsia foi observada uma área crostosa no membro torácico. O Caso 7 ocorreu em um ovino que foi trazido ao HV por apresentar uma extensa área de alopecia que se estendia da nuca à região sacral, com liquenificação e espessamento da pele, há 3 meses. $\mathrm{Na}$ propriedade foi realizado tratamento, mas não houve melhora. O Caso 8 foi trazido ao HV, por apresentar decúbito esternal e desnutrição no final da gestação.

Ocorreram dois surtos (Casos 4 e 5). No Caso 4, o surto ocorreu em um rebanho de 200 ovinos (40 cordeiros, 80 ovelhas e 80 machos de diferentes faixas etárias) afetando 16 animais. A propriedade não tinha histórico da doença anteriormente. O início dos casos ocorreu em abril de 2006 no final das chuvas, 6 ovelhas apresentaram desprendimento de pêlos com formação de crostas nas orelhas e cabeça. Posteriormente, 6 cordeiros e 4 oveIhas apresentaram lesões semelhantes. Tanto os cordeiros quanto as ovelhas apresentavam lesões de extensão variável na cabeça e orelhas com alopecia e formação de crostas (Fig.2B e 2D). No Caso 5, o surto ocorreu em um rebanho de 150 animais, 60 caprinos e 90 ovinos criados em conjunto. Desses, 40 ovinos adoeceram e 16 morreram, sendo afetados principalmente os adultos e poucos jovens. A doença não ocorreu nos caprinos. Os animais apresentaram extensas áreas de alopecia, com formação de crostas. Em alguns ovinos as lesões afetavam somente as orelhas e cabeça, enquanto que em outros as lesões se estendiam à parte superior do pescoço e todo o dorso (Fig.2A e 2C). Nos dois surtos, após o diagnóstico da doença recomendou-se o tratamento com penicilina/estreptomicina ou tetraciclinas. Segundo o clínico os animais se recuperaram.

No exame microscópico direto de crostas, coradas por Giemsa dos Casos 3, 4, 5, 7 e 8 foram observadas estruturas basofílicas filamentosas morfologicamente compatíveis com Dermatophilus congolensis. Na histologia, realizada em todos os casos, foram observadas, na epiderme, extensas áreas multifocais de hiperqueratose orto e paraqueratótica, com microabcessos intracorneais. Nestes locais foram observadas estruturas filamentosas basofílicas morfologicamente compatíveis com Dermatophilus congolensis. Na epiderme foram observadas pústulas, hiperplasia pseudoepiteliomatosa e acantose. Na derme havia um moderado infiltrado inflamatório neutrofílico e raros linfócitos e plasmócitos, localizados principalmente perto de vasos.

\section{Dermatite alérgica}

Ocorreram dois casos de dermatite alérgica, um em ovino e outro em caprino. O primeiro caso ocorreu em um ovino, macho, adulto da raça Cariri em junho de 2005, que foi trazido ao HV por apresentar prurido e áreas de alopecia e espessamento da pele, localizados nas oreIhas, focinho, pescoço, flanco esquerdo, cauda e testículos. Este animal era criado com mais um ovino na propriedade, que não adoeceu. Foi realizada biópsia cutânea. Na histologia foi observada moderada dermatite eosinofílica, caracterizada por moderado infiltrado, principalmente perivascular, de eosinófilos e raros plasmócitos e macrófagos. Havia também discreta hiperqueratose e dilatação do ducto das glândulas sudoríparas.

O outro caso ocorreu em um caprino, macho, com 8 dias de idade, sem raça definida (SRD) em março de 2006. $\mathrm{O}$ animal estava parasitado por piolhos (Bovicola caprae), apresentava prurido e múltiplas lesões pelo corpo, localizados principalmente nas orelhas, que se caracterizavam por pequenos tufos de pêlo que desprendiam quando 

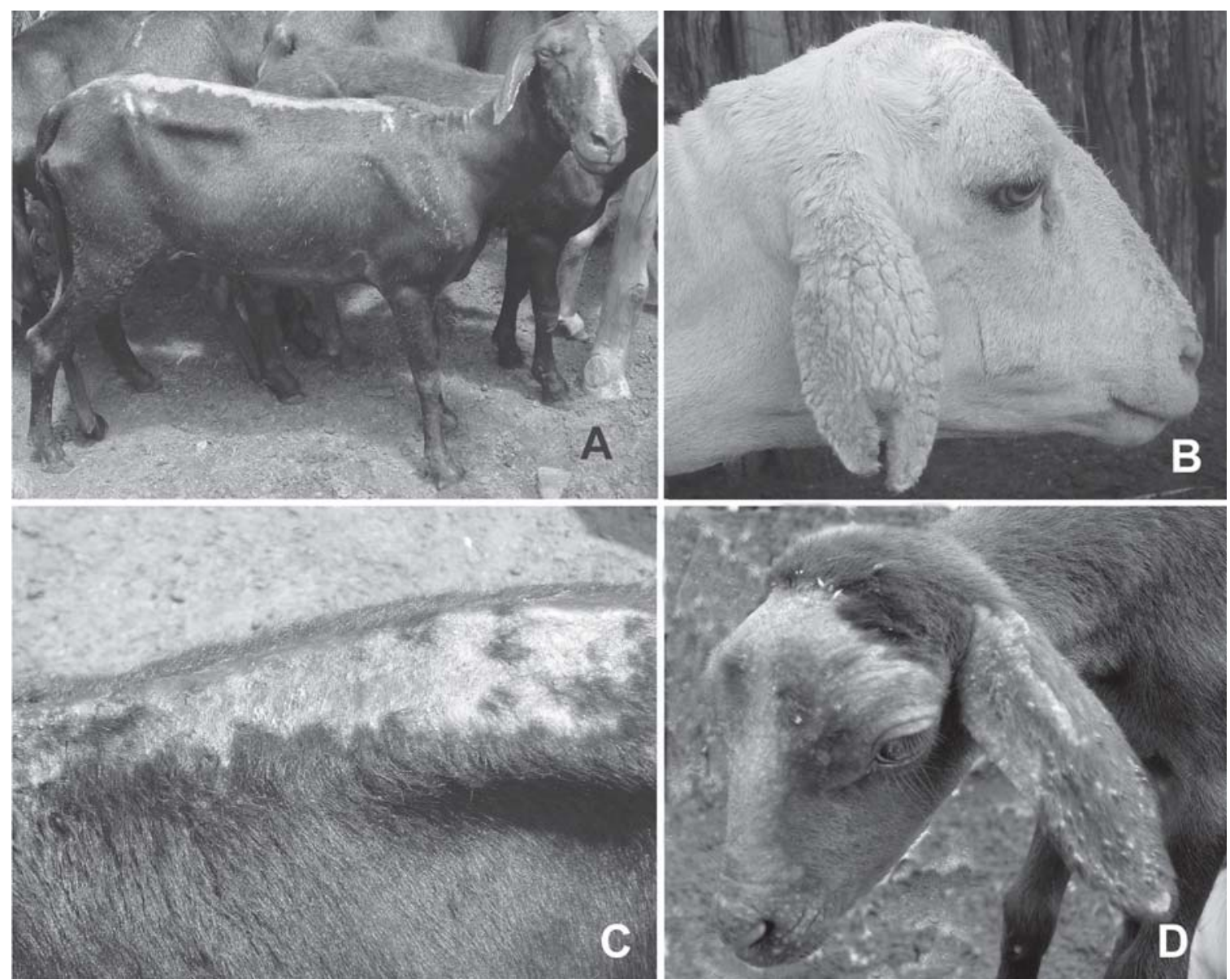

Fig.2. Dermatofilose em ovinos. (A e C) Caso 5. Observam-se extensas áreas de alopecia na cabeça, pescoço, dorso e garupa. (B) Caso 4. Observa-se a presença de crostas na orelha. (D) Caso 4 Observam-se áreas de alopecia e crostas na cabeça e orelhas.

tracionados deixando a epiderme exposta. No testículo haviam pequenas erosões provavelmente causadas por autotraumatismo. Na histologia havia dermatite eosinofílica moderada além de acantose e edema subcutâneo.

\section{Melanoma}

Ocorreram dois casos de melanoma em cabras. O primeiro caso ocorreu em uma cabra, SRD, com cinco anos de idade, que foi trazida ao HV por apresentar um tecido protruso na comissura vulvar dorsal. O outro caso ocorreu em uma cabra com dois anos de idade, que foi trazida ao HV, por apresentar lesões hiperplásicas, queratinizadas, semelhantes a verrugas, localizadas na orelha, nariz e lábio superior.

$\mathrm{Na}$ microscopia, observou-se proliferação de células com núcleos grandes arredondados, vesiculosos, levemente basofílicos, nucléolos evidentes, com citoplasma moderado pleomórfico infiltrando a epiderme e derme e sem um padrão na disposição das células. Na maioria dessas células observa-se a presença de um pigmento castanho-escuro granuloso no citoplasma. Apresentava estroma escasso e bem vascularizado e superfície da lesão ulcerada com necrose e contaminação bacteriana secundária.

\section{Epidermólise bolhosa}

Em um rebanho de 110 caprinos, 60 cabras adultas, a metade da raça Anglonubiana ou cruzas, foram cruzadas com um bode Anglonubiano nascido na própria fazenda, que segundo o proprietário havia cruzado com irmãs e filhas. Nasceram 25 cabritos, dos quais 4 , machos e fêmeas, apresentavam, ao nascimento, parte das orelhas sem pêlos. Aos 2-3 dias começavam a apresentar desprendimento da epiderme na pele das orelhas (Fig.3A) e outras regiões, assim como desprendimento da camada córnea dos cascos (Fig.3B). Alguns dias depois apresentavam lesões na boca e morriam 15 ou 20 dias após 0 parto. A orelha ficava fina e deformada e a pele se desprendia com facilidade ao passar o dedo deixando a derme exposta. Foram trazidos ao HV dois animais desta propriedade. No ano de 2004, um cabrito deste rebanho, com aproximadamente 20 dias de idade passou 20 dias no HV recebendo tratamento sintomático para as úlceras e morreu após apresentar diarréia por 4 dias. No ano de 2006, outro caprino, macho, com um mês e quinze dias, da mesma propriedade, foi trazido ao HV. Apresentava-se ativo, com apetite e com lesões ulcerativas nos cascos, gengivas e no palato duro. Após alguns dias as lesões 
progrediram, o animal estava apático, com dificuldade na alimentação e passava a maior parte do tempo em decúbito esternal devido às úlceras na boca e a perda dos cascos. Após 8 dias, o animal morreu.

$\mathrm{Na}$ necropsia, os dois animais apresentaram lesões semelhantes, caracterizadas por lesões ulcerativas da boca, língua (Fig.3C), palato duro e palato mole e oreIhas, amolecimento e descolamento dos cascos e erosões e ulcerações no esôfago, abomaso e língua. Além de lesões na pele da região abdominal ventral, cranial ao prepúcio e articulações úmero-radiais. Na histologia foi observado desprendimento sub-basal da epiderme (Fig.3D). Na ultra-estrutura da bolha, a epiderme se encontrava separada da derme e a lâmina basal aderida às células basais. Os desmossomos, hemidesmossomos e filamentos de ancoragem se encontram bem conservados. No teto da bolha, formada pela margem da lâmina densa, observou-se restos de fibrilas de ancoragem.

\section{Papilomatose}

Foi diagnoticado um caso de papilomatose em um caprino macho, raça Anglonubiana de 1 ano e 2 meses de idade. Este animal foi trazido ao HV por apresentar há
3 meses, lesões proliferativas crostosas com superfície cornificada, semelhantes a verrugas, na região nasal, palpebral e orelha características de papilomatose, que se disseminaram por todo corpo. Estas lesões quando retiradas apresentavam sangramento.

\section{Pênfigo foliáceo}

Uma cabra da raça Boer, de 2 anos e 8 meses de idade, foi trazida ao HV, com histórico de dermatite crônica. No exame clínico foram observadas extensas áreas alopécicas, bilaterais que se estendiam da região dorsal da escápula a garupa do animal, membros pélvicos e cauda. Essas eram acentuadas na região dorso-lombar e caracterizavam-se por serem esfoliativas e com crostas amareladas. No rodete coronário havia espessamento da pele e lesões crostosas. Na histologia foram observadas lesões características de pênfigo foliáceo. Este caso foi publicado por Macêdo et al. (2008).

\section{Pitiose}

Ocorreram dois surtos de pitiose em ovinos em 2004. Esses casos já foram descritos anteriormente (Tabosa et al. 2004).

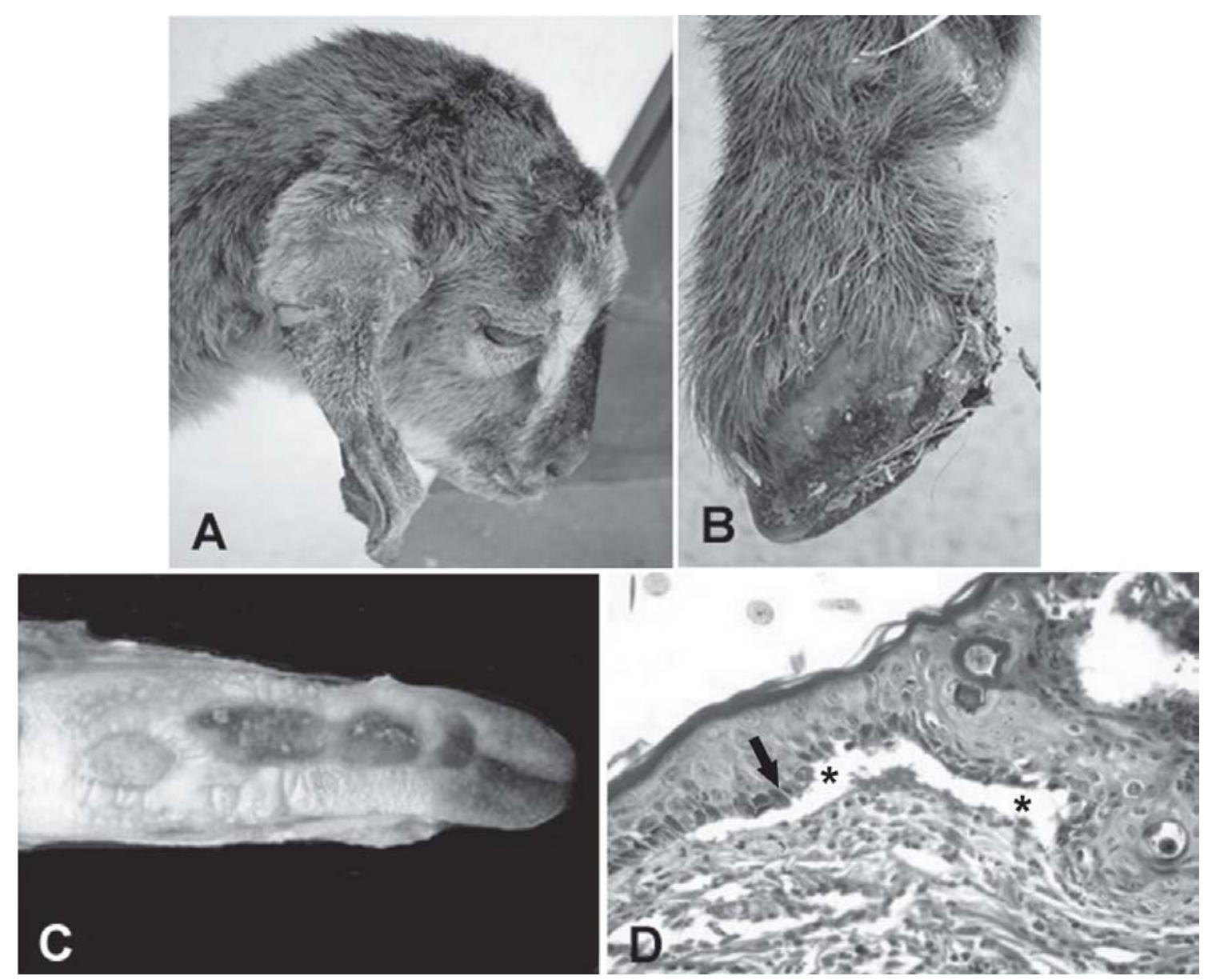

Fig.3. Epidermólise bolhosa. Caprino. (A) Alopecia e desprendimento da epiderme da orelha. (B) Desprendimento da camada córnea do casco. (C) Presença de ulceras na língua. (D) Desprendimento sub-basal da epiderme (seta) e formação de vesícula (asterisco) na pele da orelha. HE, obj.20x. 


\section{Prototecose cutânea}

Ocorreu um caso de prototecose cutânea em uma cabra que apresentava sinais respiratórios caracterizados por descarga nasal, dificuldade respiratória acompanhada de ruídos e perda de peso. Na região mucocutânea nasal e pele do lábio foi observada dermatite com nódulos proeminentes ulcerados com até $3 \mathrm{~cm}$ de diâmetro. $\mathrm{Na}$ histologia foi observada, dermatite e rinite piogranulomatosa com miríades de estruturas com as características morfológicas de Prothoteca wickerhamii. Este caso foi publicado anteriormente (Macêdo et al. 2008).

\section{Intoxicação por Leucaena leucocephala}

Um caso de intoxicação por Leucaena leucocephala ocorreu em um ovino causando alopecia no ano de 2003, esse caso e a reprodução experimental da intoxicação foram publicados por Riet-Correa et al. (2004).

\section{Fotossensibilizacão por Brachiaria brizantha}

Um surto de fotossensibilização em ovinos por Brachiaria brizantha, ocorreu em uma propriedade no município Tabira, Pernambuco. Um rebanho de 300 caprinos e ovinos estava em uma área de capim braquiária, há trinta dias. Nesta mesma área, anteriormente havia bovinos que apresentavam prurido principalmente na cabeça, porém nenhum animal morreu. Do rebanho, 80 animais adoeceram e 50 morreram, destes 30 eram ovinos. Os animais apresentam cegueira, corrimento ocular e prurido da pele evidenciada por movimentos permanentes da cabeça esfregando a mesma em objetos. Dois ovinos machos deste rebanho foram trazidos ao HV. No exame clínico os animais apresentavam dorso arqueado, congestão e icterícia de mucosas, edema de pálpebra e pêlos secos e arrepiados. Na necropsia foi observada, opacidade de córnea bilateral, difusa icterícia no subcutâneo e vísceras, fígado com coloração alaranjada, rim enegrecido com petéquias na região subcapsular e urina amarelada. Histologicamente observou-se no fígado discreta a moderada degeneração e necrose multifocal a aleatória de hepatócitos, principalmente na região periportal. Havia também múltiplos e dispersos macrófagos espumosos, além de discreta hiperplasia de células epiteliais de ductos e desorganização dos cordões de hepatócitos. Nos rins verificou-se degeneração e necrose de células epiteliais tubulares com dilatação de túbulos na região cortical externa, multifocal, moderada, associada à presença de cilindros e gotas hialinas, e também alguns cilindros granulosos na luz de alguns túbulos da região cortical e medular.

\section{Rabdomiossarcoma}

Uma cabra, SRD de 2 anos de idade foi trazida ao HV por apresentar uma massa tumoral ulcerada localizada acima do ângulo da mandíbula com evolução de aproximadamente 30 dias. Adiconalmente a cabra apresentva caquexia, pêlos opacos e quebradiços e decúbito lateral. $\mathrm{O}$ animal foi eutanasiado por estar muito debilitado e sem se alimentar.
Na necropsia foi observada uma massa tumoral ulcerada de aproximadamente $10 \mathrm{~cm}$ de diâmetro na região do ângulo da mandíbula da face esquerda. Esta massa tumoral estava infiltrando os tecidos adjacentes de tal forma que envolvia a face medial da mandíbula. Neste local havia uma fratura da mandíbula e acentuado edema circundando a lesão.

$\mathrm{Na}$ histologia foi observada proliferação de células com núcleos grandes e pleomórficos, vesiculosos e basofilia variável (ora levemente basofílico ora intensamente basofílico), nucléolos bem evidentes, ovais e basofílicos podendo haver até quatro nucléolos em cada célula, com citoplasma abundante eosinofílico e pleomórfico. Muitas destas células eram multinucleadas e estavam dispostas em feixes; o estroma de sustentação era escasso e havia infiltrado inflamatório mononuclear difuso acentuado. Observava-se uma extensa área ulcerada localizada na superfície da massa com grande quantidade de neutrófilos, restos celulares e contaminação bacteriana secundária.

\section{Casos sem diagnóstico}

Em 23 casos (19 em ovinos e 4 em caprinos) não foi coletado material para a confirmação do diagnóstico (biópsia ou raspado de pele). Estes casos foram considerados como sem diagnóstico.

\section{DISCUSSÃO}

Os resultados deste trabalho mostram que no período de janeiro de 2000 a novembro de 2006 as doenças da pele mais freqüentes no semi-árido foram as miíases, seguidas de ectima contagioso, carcinoma epidermóide e dermatofilose.

Apesar de haver maior ocorrência, os casos de miíase apresentaram uma incidência baixa, mas que se assemelha às taxas observadas no Ceará (Costa \& Vieira 1984 ), de $0,35 \%$ nos caprinos e $1,92 \%$ em ovinos. No entanto, enquanto no Ceará todas as míases foram observadas na estação chuvosa (Costa \& Vieira 1984), neste trabalho, considerando que no semi-árido a estação chuvosa vai de dezembro a junho e a seca de julho a novembro, houve uma pequena diferença de $0,5 \%$ a mais de casos durante a estação chuvosa, não havendo uma sazonalidade da enfermidade na região. Oliveira et al. (1982), em um estudo sobre a flutuação populacional de Cochliomyia hominivorax no Rio de Janeiro observaram que, mesmo havendo uma diminuição de atividade da mosca nos meses mais chuvosos, os hospedeiros são passíveis de se infestarem em qualquer época do ano. Brito et al. (2005) no estado do Maranhão, observaram que as larvas de $C$. hominivorax foram encontradas na região da cabeça, perianal, ventre e pescoço e as principais causas da presença destas larvas, segundo os tratadores, eram ferimentos com arames farpados e farpas de troncos de madeira e árvores, que servem como porta de entrada para a postura das moscas. Dos casos acompanhados no HV, em Patos, 72,22\% também apresentaram lesões nesses locais, mas as principais causas 
foram a falta de manejo sanitário dos cabritos acarretando míases no umbigo e região perineal, seguido do não tratamento de lesões causadas por traumas. Esses resultados mostram que esta enfermidade pode ser controlada pela cura do umbigo de animais jovens e pelo tratamento das lesões decorrentes de traumas. É importante, também, a inspeção diária do rebanho que contribuiria na identificação e tratamento dos animais feridos.

De acordo com Pereira \& Meireles (2007) a dermatofilose ocorre comumente em regiões tropicais e subtropicais quentes que possuam uma longa estação chuvosa. Neste trabalho foram registrados dois surtos da doença, com morbidade de $8 \%$ (Caso 4) e 44,4\% (Caso 5) e mortalidade de $17,8 \%$ (Caso 5) o que sugere que a doença, no semi-árido, em ovinos deslanados, adquire importância na época de chuvas, quando ocorrem condições climáticas favoráveis à sua ocorrência. Dermatophilus congolensis por ser considerado um agente oportunista manifesta a doença apenas quando encontra condições favoráveis a sua colonização, na época chuvosa um dos fatores que propiciam esta colonização seriam a umidade e temperatura alta, que levam ao desequilíbrio das barreiras superficiais de defesa $(\mathrm{pH}$, ácidos graxos e flora normal) (Pereira \& Meireles 2007). Os outros casos de dermatofilose foram casos isolados da doença, inclusive durante a época seca, e pareceriam estar relacionados à deficiência imunológica, debilidade ou doenças intercorrentes. As medidas de controle e profilaxia indicadas consistem em separar os animais afetados do rebanho e tratálos com antibióticos, desinfetar os materiais e instalações para evitar a transmissão da enfermidade a animais sadios e melhorar a alimentação do rebanho para aumentar a resistência dos animais (Pereira \& Meireles 2007).

Embora existam poucos dados referentes ao carcinoma epidermóide na literatura, sabe-se que essa neoplasia tem ocorrência esporádica (Fernandes 2007). Os casos desta doença observados no período de 2000-2006 no HVUFCG representaram $0,76 \%$ das doenças de caprinos e $1,54 \%$ em ovinos. Estas neoplasias podem aparecer em qualquer parte do corpo embora haja uma tendência nas áreas desprovidas de pêlos e despigmentadas, como pálpebras, orelhas, focinho vulva e períneo (Pulley \& Stannard 1990), e ocorrem, em parte, em conseqüência do efeito carcinogêncico da luz solar (Yager \& Scott 1993). Dos casos relatados, $80 \%$ das lesões também foram encontradas em locais desprovidos de pêlos, principalmente em animais de pele branca, sugerindo que no semi-árido os principais fatores determinantes da alta freqüência de carcinomas epidermóides seja a alta incidência de radiação solar em áreas despigmentadas e/ou desprovidas de pêlos. Outros fatores que também poderiam estar contribuindo para essa alta freqüência são a presença de lesões cicatriciais e traumáticas (Magnol et al. 1974) e a idade avançada dos animais (Riet-Correa et al. 1981). Segundo Riet-Correa et al. (2003) na raça Santa Inês, há 15 anos atrás, a pelagem branca era muito requisitada, sendo a incidência deste tumor muito alta, provavelmente pela in- tensa insolação no semi-árido e/ou a predisposição racial. Mais recentemente, com as mudanças de preferência para as pelagens marrom e preta, os casos diminuíram e o tumor só ocorre em animais que apresentam áreas despigmentadas, oriundos de cruzamentos com animais de pelagem diferente ou com outras raças.

Os melanomas são tumores comuns na maioria das espécies (Jones et al. 2000). Em caprinos as lesões ocorrem frequentemente em áreas expostas ao sol como oreIhas, face e períneo (Parsons et al. 1990), podendo haver metástase para linfonodos e vasos (Ramadan et al. 1988). No Brasil são escassos os dados referentes a esta neoplasia em caprinos e ovinos.

A papilomatose é uma enfermidade transmissível causada por infecção pelo papilomavírus observada freqüentemente em bovinos e com menor ocorrência em cães, gatos, ovinos e caprinos (Goldschimidt \& Hendrick 2002). Em caprinos e ovinos, normalmente as verrugas são observadas na face, orelhas e membros locomotores dianteiros (Jones et al. 2000) como no caso descrito neste trabalho.

Em um caso de dermatite alérgica sazonal o ovino acometido apresentou sinais clínicos e lesões semelhantes às descritas por Ferreira (2007), Souza et al. (2005) e Corrêa et al. (2006) que em seus relatos associam esta enfermidade a picadas de mosquitos do gênero Culicoides. Estes insetos têm sido identificados na Paraíba (Araújo Lima et al. 2004, Alves 2007) e provavelmente sejam a causa deste caso de dermatite alérgica. $O$ segundo caso de dermatite alérgica, observado em um caprino, foi causado, provavelmente, pela presença de piolhos e assemelha-se aos casos descritos por Yeruham et al. (2004).

A epidermólise bolhosa é uma doença mecanobolhosa de origem hereditária (Fine et al. 1991), descrita em diversas espécies incluindo ovinos (Alley et al. 1974, Ehrensperger et al. 1987, Bruckner-Tuderman et al. 1991, Yager \& Scott 1993) caracterizada por bolhas e ulcerações da pele e membranas mucosas nos locais de atrito. Estas bolhas tornam-se úlceras exsudativas e freqüentemente há perda dos cascos. Histologicamente, as bolhas estão repletas com um fluído proteináceo e eritrócitos. Em ovinos, a doença foi descrita nas raças Suffolk e South Dorset Down em animais que nasceram sem o colágeno tipo VII, principal componente das fibrilas de ancoragem da lâmina basal (Alley et al. 1974). Olivry et al (1999) descrevem os defeitos observados nas fibrilas de ancoragem, e que estas apresentavam-se marcadamente reduzidas ao mesmo tempo que exibiam filamentos morfologicamente rudimentares. Este é primeiro relato da doença em caprinos, sendo importante comprovar a origem hereditária da mesma, assim como a sua distribuição no rebanho caprino do Nordeste, o que possibilitaria recomendar medidas de controle.

A intoxicação por Brachiaria brizantha foi o único caso de fotossensibilização registrado em ovinos no período. Outra causa freqüente de fotossensibilização em ovinos no semi-árido é a intoxicação por Froelichia humboltiana 
(ervanço), que causa fotossensibilização primária (Pimentel et al. 2007).

Os casos de ectima contagioso, pênfigo foliáceo, protothecosis, pitiose e intoxicação por Leucaena leucocephala foram discutidos separadamente (Riet-Correa et al 2004, Tabosa et al. 2004, Macedo et al. 2008a,b, Nóbrega et al. 2008).

Agradecimentos.- Este projeto foi financiado pelo programa Institutos do Milênio (Proc.420012/2005-2). Agradecimento ao Professor Severo S. Barros, Universidade Federal de Pelotas, pela realização da microscopia eletrônica do caso de dermatólise bolhosa.

\section{REFERÊNCIAS}

Alves F.A.L. 2007. Seroepidemiologia da língua azul em carneiros das mesorregiões do sertão da Borborema, Estado da Paraíba, Brasil. Dissertação de Mestrado, Programa de Pós-Graduação em Medicina Veterinária de Pequenos Ruminantes, UFCG, Patos, PB. 46p.

Araújo Lima R.C., Almeida V.F. \& Athayde A.C. 2004. Ocorrência de Culicoides furens (Diptera: Ceratopogonidae) no município de Lagoa Seca, Paraíba. XXXI Congresso Brasileiro de Medicina Veterinária, São Luis, Maranhão.

Alley M.R., O'Hara P.J. \& Middelberg A. 1974. An epidermolysis bullosa of sheep. N. Z. Vet. J. 22:55-59.

Brito D.R.B., Santos A.C.G. \& Guerra M.S.N.C. 2005. Ectoparasitos em rebanhos de caprinos e ovinos na Microregião do Alto Mearim e Grajaú, estado do Maranhão. Revta Bras. Parasitol. Vet. 14(2):59-63.

Bruckner-Tuderman L., Guscetti F. \& Ehrensperger F. 1991. Animal model for dermolytic mechanobullous disease: Sheep with recessive dystrophic epidermolysis bullosa lack collagen VII. J. Invest. Dermatol. 124:242-251.

Corrêa T.G., Ferreira J.M., Riet-Correa G., Ruas J.L., Schild A.L., RietCorrea F., Guimarães A. \& Felippe-Bauer M.L. 2007. Seasonal allergic dermatits in sheep in southern Brazil causaed by Culicoides insignis (Diptera: Ceratopogonidae). Vet. Parasitol. 145:181-185.

Costa C.A.F. \& Vieira L.S. 1984. Ectoparasitos permanentes de caprinos e ovinos em Sobral, CE. Pesq. Agropec. Bras. 19(5):639-646.

Ehrensperger F., Hauser B. \& Wild P. 1987. Epidermolysis bullosa beim Schaflamm. Tierärztl. Umschau 42:697-700.

Fernandes C.G. 2007. Neoplasmas em ruminantes e eqüinos, p.650656. In: Riet-Correa F., Schild A.L., Lemos R.A.A. \& Borges J.R.J. (Ed.), Doenças de Ruminantes e Eqüinos. Vol.2. $3^{\text {a }}$ ed. Pallotti, Santa Maria.

Ferreira J.L.M. 2007. Dermatite alérgica sazonal, p.624-626. In: RietCorrea F., Schild A.L., Lemos R.A.A. \& Borges J.R.J. (Ed.), Doenças de Ruminantes e Eqüinos. Vol.2. 3aㅡ ed. Pallotti, Santa Maria.

Fine J.D., Bauer E.A., Briggman R.A., Carter D.M., Eady R.A.J., Esterly N.B., Holbrook K.A., Hurwitz S., Johnson L., Lin A., Pearson R. \& Sybert V.P. 1991. Revised clinical and laboratory criteria for subtypes of inherited epidermolysis bullosa: A consensus report by the Subcommittee on Diagnosis and Classification of the National Epidermolysis Bullosa Registry. J. Am. Acad. Dermatol. 14:119-135.

Goldschimidt M.H. \& Hendrick M.J. 2002. Papilloma (Cutaneous papillomatosis), p.47-48. In: Meuten D.J. (Ed.), Tumors in Domestic Animals. $4^{\text {th }}$ ed. lowa State Press, Ames.

Jones T.C., Hunt R.D. \& King N.W. 2000. Patologia Veterinária. $6^{\underline{a}}$ ed. Editora Malone, Barueri, São Paulo.

Macêdo J.T.S.A., Riet-Correa F., Dantas A.F.M. \& Simões S.V.D. 2008.
Cutaneous and nasal protothecosis in a goat. Vet. Pathol. 45:352354.

Macêdo J.T.S.A., Riet-Correa F., Dantas A.F.M. \& Simões S.V.D. 2008. Pênfigo foliáceo em cabra Boer. Ciência Rural. 38(9):2633-2635.

Magnol J.P., Cabanie P. \& Van Heberbeke G. 1974. Le cancer de l'oreille du mouton dans le sud-ouest de la France. Etude morphologique et epidemiologique. Revue Méd. Vét. 125:679-696.

Nóbrega Jr J.E., Macêdo J.T.S.A., Araújo J.A.S., Dantas A.F.M., Soares M.P. \& Riet-Correa F. 2008. Ectima contagioso em ovinos e caprinos no semi-árido da Paraíba. Pesq. Vet. Bras. 28(3):135-139.

Nogueira Filho A. 2003. Ações de fomento do Banco do Nordeste e potencialidades da caprino-ovinocultura, p.43-55. Anais do $2^{\circ}$ Simpósio Internacional sobre Caprinos e Ovinos de Corte, 29 set.-3 out. 2005, João Pessoa.

Oliveira C.M.B., Moya G.E. \& Mello R.P. 1982. Flutuação populacional de Cochliomyia hominivorax no município de Itaguaí, Rio de Janeiro. Pesq. Vet. Bras. 2(4):139-142.

Olivry T., Dunston S.M. \& Marinkovich M.P. 1999. Reduced anchoring fibril formation and collagen VII immunoreactivity in feline dystrophic epidermolysis bullosa. Vet. Pathol. 36:616-618.

Parsons P.G., Takahashi H., Candy J., Meyers B., Vickers J., Kelly W.R. Smith I. \& Spradbrow P. 1990. Histopathology of melanocytic lesions in melanoma cell line: A potencial model for human melanoma. Pigment Cell Res. 3(6):297-305. (Abstract)

Pereira D.B. \& Meireles M.C.A. 2007. Dermatofilose, p.451-457. Doenças bacterianas. In: Riet-Correa F., Schild A.L., Lemos R.A.A. \& Borges J.R.J. (Ed.), Doenças de Ruminantes e Eqüinos. Vol.1. 3를. ed., Pallotti, Santa Maria.

Pimentel L.A., Riet-Correa F., Guedes K.M.R., Macêdo J.T.S.A., Medeiros R.M.T. \& Dantas A.F.M. 2007. Primary photosensitization in equidae and ruminants in the Brazilian semi-arid caused by Froelichia humboldtiana (Amaranthaceae). Pesq. Vet. Bras. 27(1):23-28.

Pulley L.T. \& Stannard A.A. 1990. Tumors of the skin and soft tissues, p.23-87. In: Moulton J.E. (Ed.), Tumors in Domestic Animals. University California Press, Los Angeles.

Ramadan O.D., el Hassan A.M. \& Taj el Deen M.D. 1988. Malignant melanoma in goats: A clinico-pathological study. J. Comp. Pathol. 98(2):237-46.

Riet-Correa F., Cassal A.B., Scarsi R.M., Schild A.L. \& Mendez M.C. 1981. Carcinomas epidermóides em ovinos em um estabelecimento do Rio Grande do Sul. Pesq. Vet. Bras. 1(2):65-68.

Riet-Correa F., Tabosa I.M., Azevedo E.O., Medeiros R.M.T., Simões S.V.D., Dantas A.A., Alves J.C., Nobre V.M.T., Athaylde A.C., Gomes A.A. \& Lima E.F. 2003. Doenças de ruminantes e eqüinos no semi-árido da Paraíba. Semi-árido em Foco, Patos, 1:2-86.

Riet-Correa F., Barros S.S., Araújo J.A.S., Vasconcelos J.S., Medeiros R.M. 2004. Intoxicação por Leucaena leucocephala em ovinos na Paraíba. Pesq. Vet. Bras. 24(Supl.):52.

Souza T.M., Fighera R.A., Piazer J.V., Barros C.L. \& Irigoyen L.F. 2005. Dermatite alérgica sazonal em ovinos. Ciência Rural 35(2):475-477.

Tabosa I.M., Riet-Correa F., Nobre V.M.T., Azevedo E.O., Reis-Junior J.L. \& Medeiros R.M. 2004. Outbreaks of pythiosis in two flocks of sheep in Northeastern Brazil. Vet. Pathol. 41:412-415.

Yager J.A., Scott D.W. \& Wilcock B.P. 1993. The skin and appendages, p.531-737. In: Jubb K.V.F., Kennedy P.C. \& Palmer N. (Ed.), Pathology of Domestic Animals. Vol 1. 4th ed. Academic Press, San Diego.

Yeruham I., Perl S. \& Braverman Y. 2004. Seasonal allergic dermatitis in sheep associated with Ctenocephalides and Culicoides bites. Vet. Dermatol. 15:377-380. 